\title{
Venom Costs and Optimization in Scorpions
}

\author{
Edward R. J. Evans ${ }^{1 *}$, Tobin D. Northfield ${ }^{2,3}$, Norelle L. Daly ${ }^{1}$ and David T. Wilson ${ }^{1 *}$ \\ ${ }^{1}$ Centre for Molecular Therapeutics, Australian Institute of Tropical Health and Medicine, James Cook University, Cairns, \\ QLD, Australia, ${ }^{2}$ Department of Entomology, Tree Fruit Research and Extension Center, Washington State University, \\ Wenatchee, WA, United States, ${ }^{3}$ Centre for Tropical Environmental and Sustainability Science, College of Science and \\ Engineering, James Cook University, Cairns, QLD, Australia
}

Scorpions use venoms as weapons to improve prey capture and predator defense, and these benefits must be balanced against costs associated with its use. Venom costs involve direct energetic costs associated with the production and storage of toxins, and indirect fitness costs arising from reduced venom availability. In order to reduce these costs, scorpions optimize their venom use via evolutionary responses, phenotypic plasticity, and behavioral mechanisms. Over long timescales, evolutionary adaptation to environments with different selection pressures appears to have contributed to interspecific variation in venom composition and stinger morphology. Furthermore, plastic responses may allow scorpions to modify and optimize their venom composition as pressures change. Optimal venom use can vary when facing each prey item and potential predator encountered, and therefore scorpions display a range of behaviors to optimize their venom use to the particular situation. These behaviors include varying sting rates, employing dry stings, and further altering the volume and composition of venom injected. Whilst these cost-reducing mechanisms are recognized in scorpions, relatively little is understood about the factors that influence them. Here, we review evidence of the costs associated with venom use in scorpions and discuss the mechanisms that have evolved to minimize them.

Keywords: scorpion, venom, optimization, evolution, plasticity, behavior

\section{INTRODUCTION}

Venomous organisms inject chemical cocktails into their predators and prey in order to disrupt normal biological functioning in their target (Fry et al., 2009; Casewell et al., 2013). These chemical weapons are often rich in proteins, peptides, and small molecules (Inceoglu et al., 2003; Escoubas et al., 2008; Calvete et al., 2009; Fry et al., 2009; Villar-Briones and Aird, 2018). Whilst venom provides survival benefits by aiding in prey capture and predator defense, the benefits come with costs. These costs are two-fold, involving direct energetic costs associated with production and storage of toxins (McCue, 2006; Nisani et al., 2007, 2012), and further indirect costs associated with a reduced capacity to capture prey or defend when supplies are depleted. Whilst these costs have different types of impacts on venomous animals, the methods to reduce these costs can overlap. It has been proposed that due to costs associated with venom use, organisms will meter/optimize the volume of venom they inject in order to use their venom as economically as possible in different situations (Hayes et al., 2002; Wigger et al., 2002; Hayes, 2008; Morgenstern and King, 2013). Research into optimal venom use has primarily focussed on snakes (Hayes, 1995, 2008; Hayes et al., 2002; Young et al., 2002), spiders (Wigger et al., 2002; Wullschleger and Nentwig, 2002; Hostettler and Nentwig, 2006; Nelsen et al., 2014; Cooper et al., 2015), and scorpions (Edmunds and Sibly, 2010; Nisani and Hayes, 2011; Lira et al., 2017), with the latter being the focus of this review. 
Scorpions utilize venom to both capture prey and defend against predators, which can include organisms with very different physiologies and susceptibility to venom components (Gangur et al., 2017; van der Meijden et al., 2017). Over 400 million years of evolution (Dunlop and Selden, 2009) have led scorpions to develop a wide range of mechanisms that help minimize the costs of venom use. Successful prey capture and predator defense will ultimately affect a scorpion's evolutionary fitness, and therefore selection on venom composition and concentration is generally influenced by both prey and/or predators (Tian et al., 2008; Weinberger et al., 2009; Gangur et al., 2018). As selection pressures vary between environments, so will optimal investment in venom (Gangur et al., 2018). Scorpions adapted to different ecological niches often show large differences in venom composition (de la Vega et al., 2010) and stinger morphology (van der Meijden et al., 2013; van der Meijden and Kleinteich, 2017), and this likely reflects responses to different selection pressures.

\section{THE COSTS OF VENOM USE IN SCORPIONS}

\section{Direct}

Research on the energetic demands of venom use have focussed on costs of production, rather than maintenance, as it is difficult to measure the energy used in maintaining and storing toxins experimentally. Nisani et al. (2007) showed that after depleting the venom glands of scorpions (Parabuthus transvaalicus), metabolic rates increased by 39\% during the first 3 days of regeneration. A later study (Nisani et al., 2012) found milked $P$. transvaalicus had on average a $21 \%$ higher metabolic rate than un-milked scorpions during the first 8 days of regeneration, but in this second study the rate did not rise as high during the first 3 days (Nisani et al., 2007). Metabolic rates fluctuated throughout the experiment, and the authors suggested this likely reflected the asynchronous regeneration of toxins (Nisani et al., 2012). Whilst differences were observed between the studies, both identify a large increase in metabolic rate above baseline levels, indicating that in scorpions venom production is an important energetic expense (Nisani et al., 2007, 2012). These studies also likely underestimate total energetic costs, as venom regeneration can take longer than 8 days to complete (Carcamo-Noriega et al., 2019). Furthermore, scorpion venom varies between species in complexity, toxins utilized, and volume stored and injected (de la Vega et al., 2010; Sunagar et al., 2013; van der Meijden et al., 2015); all of which alter energy requirements. Energetic costs are also dependent on the metabolic rate, which is likely to vary between species adapted to different ecological niches. Furthermore, as scorpions are ectotherms their metabolic rate will vary with environmental conditions, as Nime et al. (2013) showed scorpion activity is positively correlated with temperature.

\section{Indirect}

Indirect costs are associated with the ecological limitations arising from depleted venom supplies, such as increased predation risk or reduced ability to capture prey. Scorpions can store a limited volume of venom (van der Meijden et al., 2015), and regeneration of toxins can take at least 2 weeks to be complete (Carcamo-Noriega et al., 2019), reducing the ability to use venom for prey capture and predator defense until venom supplies are restored. Ecological costs of venom depletion cannot easily be quantified, as they will vary widely between species and environments with fluctuating selection pressures. Nonetheless, evaluation of behavioral changes that arise when venom stores are depleted may serve as evidence of ecological costs. Such a behavioral response has yet to be reported in scorpions, but some spiders with depleted venom supplies will adapt their hunting behavior to target easily caught prey, as has been found in the wandering spider Cupiennius salei (Wullschleger and Nentwig, 2002). Scorpions and spiders often share many of their natural predators and prey items, therefore the ecological costs of venom depletion in both organisms may bear some similarity. Comparable behaviors in scorpions might include a switch to smaller prey that can be successfully captured with only the pedipalps while venom is replenishing.

\section{THE EVOLUTION OF OPTIMAL VENOM USE}

Compared with other venomous taxa, scorpions are unusual in that they possess two main weapons: their stinging apparatus and their pedipalps. Species vary in their relative investment in these two weapons depending on their ecological niche, leading to the great morphological diversity in scorpion stinging apparatus and pedipalps seen between species (Figure 1) (van der Meijden et al., 2013). Burrowing species, such as members of the family Scorpionidae, are often sit-and-wait predators (Hadley and Williams, 1968; Bub and Bowerman, 1979; Shachak and Brand, 1983; Shivashankar, 1994), and possess large pedipalps that can be used to dig, grab passing prey, and block predators from entering their burrow (van der Meijden et al., 2010). Large pedipalps are often accompanied by a small stinging apparatus. Small tail size may be due to a trade-off in investment between pedipalps and stinging apparatus (van der Meijden et al., 2013), or a reduced tail may simply improve mobility in the confines of a burrow. Vagrant scorpion species, such as many members of the family Buthidae, have no permanent residence and forage more actively (Hadley and Williams, 1968). This group of scorpions generally rely more heavily on their sting to capture prey and defend themselves, and have evolved powerful and highly mobile tails (Warburg, 1998; Coelho et al., 2017). Many of these scorpions have developed potent venom, and the family Buthidae contains all species with medically significant stings (Santos et al., 2016). Buthids often possess small pedipalps, suggesting an evolutionary trade-off between pedipalps and stinging apparatus may be present (van der Meijden et al., 2013), and/or small pedipalps may improve mobility and energetic efficiency while actively foraging. The evolution of potent venom in buthids may further have reduced the advantages that large pedipalps provide, making them energetically unfavorable. 


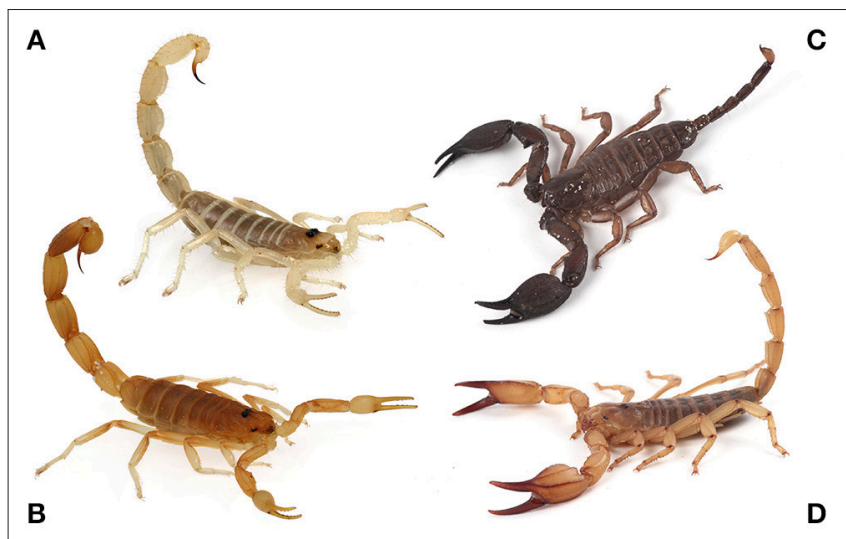

FIGURE 1 | Morphological comparison of four Australian scorpions. (A) Australobuthus xerolimniorum (Buthidae) (B) Lychas buchari (Buthidae) (C) Hormurus waigiensis (Hormuridae) (D) Urodacus sp. (Urodacidae). A. xerolimniorum and $L$. buchari are more vagrant and active foragers, and have evolved relatively small chelicerae and thick powerful tails. $H$. waigiensis and Urodacus sp. are burrowing species, and have evolved larger chelicerae and smaller stinging apparatuses. Photographs by Edward Evans.

\section{BEHAVIORAL MECHANISMS TO OPTIMIZE VENOM USE}

Optimal use of venom will vary between each interaction with prey and predators, influenced by the size and identity of the prey/predator. This has led scorpions to evolve a range of behavioral mechanisms allowing them to optimize their venom use when facing specific prey (Edmunds and Sibly, 2010) and under particular levels of threat (Nisani and Hayes, 2011).

\section{The "Decision" to Sting}

To reduce the costs associated with unnecessary venom use, scorpions adapt their hunting strategies to the particular prey items targeted (Simone et al., 2018), and are less likely to use venom when capturing small or easily subdued prey (Rein, 1993; Edmunds and Sibly, 2010). Spiders appear to target the injection of their venom toward the thorax or head of prey items to maximize venom efficiency (Wigger et al., 2002; Carlson et al., 2014). However, to our knowledge it is not known if scorpions seek to apply stings to an optimal location, or if an optimal sting location even exists, as one study on Bothriurus bonariensis found that sting location did not affect the time taken to subdue prey (Simone et al., 2018).

Both the size and activity of prey items can influence a scorpion's choice to sting, as Parabuthus liosoma, Parabuthus pallidus and Hadrurus spadix sting larger and more active prey items more frequently (Rein, 1993; Edmunds and Sibly, 2010). Rein (1993) observed that the scorpions did not use their sting immediately when encountering prey, but would rather grab with their pedipalps and apply stings if the prey continued to struggle, presumably to minimize venom use whilst ensuring predation success. Ontogenetic changes in stinging behavior can also be used to optimize venom use. Older Paruroctonus boreus and Pandinus imperator use their larger pedipalps to overpower prey and sting less often, avoiding using venom (Cushing and Matherne, 1980; Casper, 1985).

In addition to trade-offs between the use of venom and pedipalps for prey capture, there may be trade-offs in venom use and mobility when avoiding predation, as faster scorpions appear less likely to sting predators (Carlson et al., 2014; Miller et al., 2016). For example, female Centuroides vittatus scorpions that are heavier and less mobile, are more likely to sting a potential predator than males, which are more likely to sprint to safety (Carlson et al., 2014; Miller et al., 2016). Furthermore, within each sex, sprint speed decreases and sting rate increases with mass, indicating that higher rates of aggression are associated with reduced mobility (Carlson et al., 2014; Miller et al., 2016). Through fleeing, the males and smaller scorpions are not only able to avoid being eaten, but they also save their venom supply for future encounters and do not need to expend energy regenerating toxins, thus reducing ecological and energetic venom costs.

Unlike other scorpions, seven species of Parabuthus spray venom defensively, which may cause irritation to the sensitive tissues, such as eyes, of predators (Newlands, 1974; Nisani and Hayes, 2015). P. transvaalicus defensively spray when presented with both air-flow and touch stimuli simultaneously, suggesting the behavior may be optimized toward high-threat scenarios where defensive tactics must be implemented before a predator gets close enough to sting (Nisani and Hayes, 2015). These scorpions are often attacked by predators such as grasshopper mice, which disarm scorpions by biting off their tails, and therefore place their face in close proximity to the telson (Nisani and Hayes, 2015). Compared with injection, sprayed venom has a higher risk of missing its target, likely increasing the costs of venom necessary to deter predators. However, these costs are likely offset by the advantage of deterring predators while the predator is still at a distance.

\section{"Dry" Stings}

Scorpions can still avoid venom use when stinging in defensive encounters by employing "dry" stings, where no venom is injected. Scorpions readily utilize dry stings in defensive situations (Nisani and Hayes, 2011; Lira et al., 2017; Rasko et al., 2018). The factors that determine whether venom is injected in a sting, however, are currently unclear. In P. transvaalicus, dry stinging behavior is correlated with threat level, with the scorpions employing dry stings more frequently when the threat level is low (Nisani and Hayes, 2011). Additionally, this study suggests $P$. transvaalicus, when induced to sting multiple times in succession, use dry stings more frequently early in the stinging sequence and are more likely to inject venom as the threat persists (Nisani and Hayes, 2011). The combination of these results provides evidence that scorpions use dry stings in low threat situations to optimize their venom use. In contrast to the findings by Nisani and Hayes (2011) studies on dry stinging behavior in other scorpion species have produced differing results. Lira et al. (2017) presented Tityus stigmurus with the same "low-threat" and "high-threat" stimuli described by Nisani and Hayes (2011), and found no correlation between dry sting rate and threat level. Furthermore, it has been shown that repeated simulated attacks 
against Hadrurus arizonensis lead to an increase in dry sting rate, despite venom remaining in the gland (Rasko et al., 2018). This latter result seems counter-intuitive, as scorpions might be expected to increase their defensive investment as a threat persists. Whilst the studies investigating the factors influencing dry stinging behavior in scorpions are limited, the evidence supports the idea that at least some scorpion species utilize dry stings as a means to optimize their venom in defensive contexts (Nisani and Hayes, 2011), while others may not (Lira et al., 2017; Rasko et al., 2018). Further research should aim to identify whether interspecific differences are truly occurring, or if methodological differences between the studies are responsible for the observed differences. Furthermore, it is not currently known if scorpions utilize dry stings as a tactic to save venom when capturing prey, as spiders use dry bites (Malli et al., 1998; Wigger et al., 2002). Spiders, however, have the ability to masticate their prey with their fangs, but the dry sting of a scorpion provides comparatively little aid in the incapacitation of prey. It is therefore unlikely that scorpions use dry stings to save venom when targeting prey.

\section{Volume Injected}

While scorpion stinging behavior involves a dichotomy between dry stings vs. stings with venom injected, scorpions also have the ability to vary the volume of venom they inject, both within each sting and through the application of multiple stings (Nisani and Hayes, 2011; van der Meijden et al., 2015). P. transvaalicus injected twice as much venom per single sting in highthreat situations compared with low-threat situations, indicating scorpions may use this tactic to vary their defensive investment in response to perceived threat level. The defensive sprays of $P$. transvaalicus display variable duration and flow rate suggesting the volume expelled could be controlled by contraction of the venom gland, but it is not currently known if the volume sprayed is influenced by threat level (Nisani and Hayes, 2015).

The volume injected in single stings may be limited by morphological constraints, or the time that the aculeus is pierced into the target (van der Meijden et al., 2015). When scorpions are faced with repeated attacks from predators, they will continue to defensively sting as the attacks continue. Experiments into the defensive investment of scorpions in response to predation threat suggest that scorpions will repeatedly sting predators as the threat persists (Lira et al., 2017), but it is unclear whether the investment per attack increases or decreases with sting number (Nisani and Hayes, 2011; Rasko et al., 2018). Targeting prey, scorpions often hold on with their pedipalps and judiciously apply stings as the prey continues to struggle (Casper, 1985; Rein, 1993). The rate of stings increases with both prey size and activity (Edmunds and Sibly, 2010), suggesting that scorpions are being frugal with their venom, and only apply extra stings as necessary.

\section{Composition Injected}

In addition to reducing venom costs by metering the volume of venom they inject, scorpions are able to alter the composition of venom injected into their target and avoid unnecessarily injecting costly venom components. Scorpion venom is heterogeneous and changes in composition as it is expelled from the aculeus

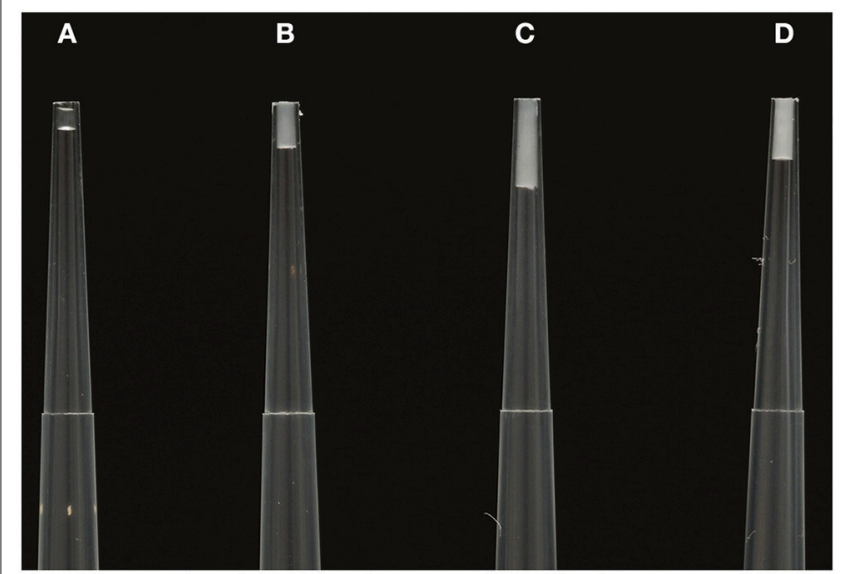

FIGURE 2 | From (A-D)-consecutive venom secretions collected from Hormurus waigiensis during one milking event using electrostimulation of the venom gland. (A) The initial secretion is relatively clear, containing the compositionally simple prevenom. (B) The secretion changes from clear to milky (C,D). The later venom secretions are comparatively opaque and white, representing the peptide/protein rich mixture. Photograph by Edward Evans.

(Figure 2). As the venom is secreted from the aculeus tip, the initial expulsion is a clear liquid, followed by an opalescent liquid, and finally turns milky colored and viscous (Yahel-Niv and Zlotkin, 1979). These different secretions also vary in toxicity (Yahel-Niv and Zlotkin, 1979). Inceoglu et al. (2003) found that the initial clear secretion in $P$. transvaalicus constituted around $5 \%$ of the total venom volume within the gland, and they termed this "prevenom". Prevenom and main milky venom have distinct compositions and modes of action in both invertebrate and vertebrate targets (Inceoglu et al., 2003). The different mode of actions of prevenom and main venom may act together to induce greater toxicity, in a similar way to the toxin cabals employed by cone snails which target different pathways simultaneously (Olivera et al., 1999; Inceoglu et al., 2003). P. transvaalicus prevenom was found to contain six-times less peptide and protein concentration compared to the main venom, but a 16-fold higher potassium $\left(\mathrm{K}^{+}\right)$salt concentration (Inceoglu et al., 2003). The authors suggested this extremely high $\mathrm{K}^{+}$concentration causes large and rapid depolarization of nerves in the target, causing quick paralysis in insects and pain in vertebrates (Inceoglu et al., 2003). Prevenom not only contains a much lower peptide/protein concentration, but a comparatively simplistic composition (Inceoglu et al., 2003). It is therefore expected that prevenom is metabolically cheaper to produce than the main venom, as $\mathrm{K}^{+}$salt likely requires less energy to be replenished than peptides requiring production and folding (Inceoglu et al., 2003). The relative costs of prevenom vs. main venom have not been calculated experimentally, but in P. transvaalicus prevenom components appear to regenerate quickly and at little metabolic cost compared with other toxins (Nisani et al., 2012). Prevenom may therefore have evolved as a mechanism to avoid injecting larger volumes of peptide rich mixtures, thereby minimizing both metabolic and ecological 
costs of depletion, although this connection is difficult to test experimentally (Nisani et al., 2012).

By using prevenom first, scorpions can save their main peptide-rich venom for high-threat situations or when initially low-threat situations escalate. This hypothesis is supported by evidence that the composition of venom (prevenom vs. main venom) scorpions inject is context dependent. In lowthreat situations, scorpions are able to avoid injecting their metabolically "expensive" mixtures of toxins, by injecting only prevenom (Nisani and Hayes, 2011). P. transvaalicus inject their main venom more frequently in high-threat situations, and in later stings when induced to sting repeatedly at both low and high threat levels (Nisani and Hayes, 2011). Furthermore, in lowthreat situations, T. stigmurus injected prevenom in all trials, but when faced with the high-threat treatments most of the scorpions injected their main milky venom secretion (Lira et al., 2017). The use of prevenom in low threat situations not only minimizes metabolic costs but also reduces ecological costs, as prevenom appears to regenerate faster than the main venom components (Nisani et al., 2012).

\section{ADAPTIVE PLASTICITY}

Recent evidence suggests scorpions can modify their venom composition in response to predator exposure (Gangur et al., 2017). Repeated periodical encounters with a surrogate vertebrate predator (a taxidermied mouse) over a 6 week period led Hormurus waigiensis to appear to produce a higher relative abundance of some vertebrate specific toxins used in defensive situations, and a lower relative abundance of certain toxins specific to their invertebrate prey (Gangur et al., 2017). This study provided the first evidence for adaptive plasticity in venom compositions, and suggested it has evolved as a mechanism to allow for the optimization of venom use (Gangur et al., 2017). Modification of venom composition in response to environmental pressures could allow scorpions to further optimize venom use in different environments. In environments with few predators, scorpions may not require large quantities of defensive toxins, but as predator abundance increases so does the need to defend themselves. Therefore, ability to plastically change venom composition can allow scorpions to prioritize their resources and minimize the costs of venom use. It is currently unclear what environmental cues (e.g., olfactory) led to the plastic response observed by Gangur et al. (2017). Furthermore, it is unclear if the response was targeted specifically at the presence of the mouse, or if it was a uniform response to increased predation pressure.

Unlike the response from simulated top-down predation pressure, Gangur et al. (2017) did not identify changes in venom composition in response to a scavenging vs. predacious diet, where venom is not required for prey capture. This may be due to the unpredictable nature of scavenging, and the potential need to kill prey in the future, regardless of current carrion availability. Alternatively, venom may need to be maintained for its defensive function. In contrast, it may also be that experimental conditions do not represent the bottom-up pressures experienced in the wild, as crickets may be more easily subdued than natural prey items. $H$. waigiensis is a burrowing species that has evolved large pedipalps and a small stinging apparatus, and further studies should evaluate whether more active species that rely more heavily on their sting to capture prey respond differently to a changing diet.

\section{CONCLUSIONS AND FUTURE DIRECTIONS}

Scorpions experience direct costs associated with the production and storage of toxins, and indirect costs associated with impaired ecological function when their venom is depleted. Optimal venom use minimizes these costs, maximizing the survival benefit venom provides. On the broadest scales, optimal venom investment has contributed to the divergence of stinger morphology and venom compositions between species adapted to different environments (Tian et al., 2008; Sunagar et al., 2013; van der Meijden et al., 2013). Optimal venom use can be influenced by factors such as prey/predator identity, and scorpions therefore utilize a suite of behavioral tactics to minimize waste. These include varying sting frequency, employing dry stings, and further controlling the volume and composition of venom injected (Nisani and Hayes, 2011). Scorpions may also plastically adapt their venom composition (Gangur et al., 2017), allowing them to optimize venom use as selection pressures change. Whilst the presence of these mechanisms and behaviors are well-documented, the factors influencing them are poorly understood. Current knowledge of venom optimization has generally relied upon correlative research, where the selective forces driving the correlations are inferred, rather than directly measured. There is evidence of venom costs, benefits for prey capture and predator defense, and behavioral and trait phenotypes that appear to reduce these costs and maximize benefits. However, there is little direct evidence tying changes in phenotypes to changes in costs or benefits to describe a mechanistic link. Controlled selection experiments or phylogenetic studies that consider species interactions can help describe links between selection and evolutionary response in arms races (Pimentel, 1968; Kursar et al., 2009; Toju et al., 2011; Betts et al., 2018), and may help better describe how observed venom optimization mechanisms have evolved. Future work is needed to investigate whether observed changes are due to adaptive responses or physiological limitations, the extent that these mechanisms are influenced by the environment, and how widespread they are across different scorpion species.

\section{AUTHOR CONTRIBUTIONS}

The manuscript was written by EE and edited by TN, DW, and ND.

\section{FUNDING}

The Northcote Trust supports EE with a Northcote Graduate Scholarship. 


\section{REFERENCES}

Betts, A., Gray, C., Zelek, M., MacLean, R. C., and King, K. C. (2018). High parasite diversity accelerates host adaptation and diversification. Science 360, 907-911. doi: $10.1126 /$ science.aam 9974

Bub, K., and Bowerman, R. F. (1979). Prey capture by the scorpion Hadrurus arizonensis Ewing (Scorpiones: Vaejovidae). J. Arachnol. 1979, 243-253.

Calvete, J. J., Sanz, L., Angulo, Y., Lomonte, B., and Gutiérrez, J. M. (2009). Venoms, venomics, antivenomics. FEBS Lett. 583, 1736-1743. doi: 10.1016/j.febslet.2009.03.029

Carcamo-Noriega, E. N., Possani, L. D., and Ortiz, E. (2019). Venom content and toxicity regeneration after venom gland depletion by electrostimulation in the scorpion Centruroides limpidus. Toxicon 157, 87-92. doi: 10.1016/j.toxicon.2018.11.305

Carlson, B. E., McGinley, S., and Rowe, M. P. (2014). Meek males and fighting females: sexually-dimorphic antipredator behavior and locomotor performance is explained by morphology in bark scorpions (Centruroides vittatus). PLoS ONE 9:e97648. doi: 10.1371/journal.pone.0097648

Casewell, N. R., Wüster, W., Vonk, F. J., Harrison, R. A., and Fry, B. G. (2013). Complex cocktails: the evolutionary novelty of venoms. Trends Ecol. Evol. 28, 219-229. doi: 10.1016/j.tree.2012.10.020

Casper, G. S. (1985). Prey capture and stinging behavior in the emperor scorpion, Pandinus imperator (Koch)(Scorpiones, Scorpionidae). J. Arachnol. $1985,277-283$.

Coelho, P., Kaliontzopoulou, A., Rasko, M., and Meijden, A. (2017). A 'striking' relationship: scorpion defensive behaviour and its relation to morphology and performance. Funct. Ecol. 31, 1390-1404. doi: 10.1111/1365-2435.12855

Cooper, A. M., Nelsen, D. R., and Hayes, W. K. (2015). The strategic use of venom by spiders. Evol. Venom. Anim. Toxins 2015, 1-18. doi: 10.1007/978-94-007-6727-0_13-1

Cushing, B. S., and Matherne, A. (1980). Stinger utilization and predation in the scorpion Paruroctonus boreus. Great Basin Nat. 1980, 193-195.

de la Vega, R. C. R., Schwartz, E. F., and Possani, L. D. (2010). Mining on scorpion venom biodiversity. Toxicon 56, 1155-1161. doi: 10.1016/j.toxicon.2009.11.010

Dunlop, J. A., and Selden, P. A. (2009). Calibrating the chelicerate clock: a paleontological reply to Jeyaprakash and Hoy. Exp. Appl. Acarol. 48:183. doi: 10.1007/s10493-009-9247-1

Edmunds, M. C., and Sibly, R. M. (2010). Optimal sting use in the feeding behavior of the scorpion Hadrurus spadix. J. Arachnol. 38, 123-125. doi: 10.1636/Hi09-38.1

Escoubas, P., Quinton, L., and Nicholson, G. M. (2008). Venomics: unravelling the complexity of animal venoms with mass spectrometry. J. Mass Spectr. 43, 279-295. doi: 10.1002/jms.1389

Fry, B. G., Roelants, K., Champagne, D. E., Scheib, H., Tyndall, J. D., King, G. F., et al. (2009). The toxicogenomic multiverse: convergent recruitment of proteins into animal venoms. Annu. Rev. Genomics Hum. Genet. 10, 483-511. doi: 10.1146/annurev.genom.9.081307.164356

Gangur, A. N., Seymour, J. E., Liddell, M. J., Wilson, D., Smout, M. J., and Northfield, T. D. (2018). When is overkill optimal? Tritrophic interactions reveal new insights into venom evolution. Theor. Ecol. 11, 141-149. doi: 10.1007/s12080-017-0354-z

Gangur, A. N., Smout, M., Liddell, M. J., Seymour, J. E., Wilson, D., and Northfield, T. D. (2017). Changes in predator exposure, but not in diet, induce phenotypic plasticity in scorpion venom. Proc. R. Soc. B Biol. Sci. 284:20171364. doi: $10.1098 /$ rspb.2017.1364

Hadley, N. F., and Williams, S. C. (1968). Surface activities of some North American scorpions in relation to feeding. Ecology 49, 726-734. doi: $10.2307 / 1935535$

Hayes, W. K. (1995). Venom metering by juvenile prairie rattlesnakes, Crotalus v. viridis: effects of prey size and experience. Anim. Behav. 50, 33-40. doi: 10.1006/anbe.1995.0218

Hayes, W. K. (2008). "The snake venom-metering controversy: levels of analysis, assumptions, and evidence," in The Biology of Rattlesnakes, eds W. K. Hayes, K. R. Beaman, M. D. Cardwell, and S. P. Bush (Loma Linda, CA: Loma Linda University Press), 191-220.

Hayes, W. K., Herbert, S. S., Rehling, G. C., and Gennaro, J. F. (2002). "Factors that influence venom expenditure in viperids and other snake species during predatory and defensive contexts," in Biology of the Vipers, eds G. W. Schuett,
M. Hoggren, M. E. Douglas, H. W. Greene (Eagle Mountain: Eagle Mountain Publishing), 207-233.

Hostettler, S., and Nentwig, W. (2006). Olfactory information saves venom during prey-capture of the hunting spider Cupiennius salei (Araneae: Ctenidae). Funct. Ecol. 20, 369-375. doi: 10.1111/j.1365-2435.2006.01103.x

Inceoglu, B., Lango, J., Jing, J., Chen, L., Doymaz, F., Pessah, I. N., et al. (2003). One scorpion, two venoms: prevenom of Parabuthus transvaalicus acts as an alternative type of venom with distinct mechanism of action. Proc. Natl. Acad. Sci. U.S.A. 100, 922-927. doi: 10.1073/pnas.242735499

Kursar, T. A., Dexter, K. G., Lokvam, J., Pennington, R. T., Richardson, J. E., Weber, M. G., et al. (2009). The evolution of antiherbivore defenses and their contribution to species coexistence in the tropical tree genus Inga. Proc. Natl. Acad. Sci. U.S.A. 106, 18073-18078. doi: 10.1073/pnas.0904786106

Lira, A. F., Santos, A. B., Silva, N. A., and Martins, R. D. (2017). Threat level influences the use of venom in a scorpion species, Tityus stigmurus (Scorpiones, Buthidae). Acta Ethol. 20, 291-295. doi: 10.1007/s10211-017-0274-3

Malli, H., Imboden, H., and Kuhn-Nentwig, L. (1998). Quantifying the venom dose of the spider Cupiennius salei using monoclonal antibodies. Toxicon 36, 1959-1969. doi: 10.1016/S0041-0101(98)00120-2

McCue, M. D. (2006). Cost of producing venom in three North American pitviper species. Copeia 2006, 818-825. doi: 10.1643/0045-8511(2006)6[818:COPVIT]2. $0 . \mathrm{CO} ; 2$

Miller, D., Jones, A., Goldston, J., Rowe, M., and Rowe, A. (2016). Sex differences in defensive behavior and venom of the striped bark scorpion Centruroides vittatus (Scorpiones: Buthidae). Integr. Comp. Biol. 56, 1022-1031. doi: $10.1093 /$ icb/icw098

Morgenstern, D., and King, G. F. (2013). The venom optimization hypothesis revisited. Toxicon 63, 120-128. doi: 10.1016/j.toxicon.2012.11.022

Nelsen, D. R., Kelln, W., and Hayes, W. K. (2014). Poke but don't pinch: risk assessment and venom metering in the western black widow spider, Latrodectus hesperus. Anim. Behav. 89, 107-114. doi: 10.1016/j.anbehav.2013.12.019

Newlands, G. (1974). The venom-squirting ability of Parabuthus scorpions (Arachnida: Buthidae). South African Journal of Medical Sciences 39, 175-178.

Nime, M. F., Casanoves, F., Vrech, D. E., and Mattoni, C. I. (2013). Relationship between environmental variables and surface activity of scorpions in the Arid Chaco ecoregion of Argentina. Inverteb. Biol. 132, 145-155. doi: $10.1111 /$ ivb.12019

Nisani, Z., Boskovic, D. S., Dunbar, S. G., Kelln, W., and Hayes, W. K. (2012). Investigating the chemical profile of regenerated scorpion (Parabuthus transvaalicus) venom in relation to metabolic cost and toxicity. Toxicon 60 , 315-323. doi: 10.1016/j.toxicon.2012.04.343

Nisani, Z., Dunbar, S. G., and Hayes, W. K. (2007). Cost of venom regeneration in Parabuthus transvaalicus (Arachnida: Buthidae). Comp. Biochem. Physiol. A Mol. \& Integr. Physiol. 147, 509-513. doi: 10.1016/j.cbpa.2007.01.027

Nisani, Z., and Hayes, W. K. (2011). Defensive stinging by Parabuthus transvaalicus scorpions: risk assessment and venom metering. Anim. Behav. 81, 627-633. doi: 10.1016/j.anbehav.2010.12.010

Nisani, Z., and Hayes, W. K. (2015). Venom-spraying behavior of the scorpion Parabuthus transvaalicus (Arachnida: Buthidae). Behav. Processes 115, 46-52. doi: 10.1016/j.beproc.2015.03.002

Olivera, B. M., Walker, C., Cartier, G. E., Hooper, D., Santos, A. D., Schoenfeld, R., et al. (1999). Speciation of cone snails and interspecific hyperdivergence of their tenom peptides: potential evolutionary significance of introns. Ann. N. Y. Acad. Sci. 870, 223-237. doi: 10.1111/j.1749-6632.1999.tb08883.x

Pimentel, D. (1968). Population regulation and genetic feedback. Science 159, 1432-1437. doi: 10.1126/science.159.3822.1432

Rasko, M., Coelho, P., Simone, Y., and van der Meijden, A. (2018). How to attack a scorpion: venom metering during a repeated attack. Anim. Behav. 145, 125-129. doi: 10.1016/j.anbehav.2018.09.019

Rein, J. O. (1993). Sting use in two species of Parabuthus scorpions (Buthidae). J. Arachnol. 1993, 60-63.

Santos, M. S., Silva, C. G., Neto, B. S., Júnior, C. R. G., Lopes, V. H., Júnior, A. G. T., et al. (2016). Clinical and epidemiological aspects of scorpionism in the world: a systematic review. Wild. Environ. Med. 27, 504-518. doi: 10.1016/j.wem.2016.08.003

Shachak, M., and Brand, S. (1983). The relationship between sit and wait foraging strategy and dispersal in the desert scorpion, Scorpio maurus palmatus. Oecologia 60, 371-377. doi: 10.1007/BF00376854 
Shivashankar, T. (1994). Advanced sub social behaviour in the scorpion Heterometrus fulvipes Brunner (Arachnida). J. Biosci. 19, 81-90. doi: 10.1007/BF02703471

Simone, Y., Garcia, L. F., Lacava, M., van der Meijden, A., and Viera, C. (2018). Predatory versatility in females of the scorpion Bothriurus bonariensis (Scorpiones: Bothriuridae): overcoming prey with different defensive mechanisms. J. Insect Behav. 2018, 1-14. doi: 10.1007/s10905-018-9 $677-\mathrm{x}$

Sunagar, K., Undheim, E., Chan, A., Koludarov, I., Muñoz-Gómez, S., Antunes, A., et al. (2013). Evolution stings: the origin and diversification of scorpion toxin peptide scaffolds. Toxins 5, 2456-2487. doi: 10.3390/toxins5122456

Tian, C., Yuan, Y., and Zhu, S. (2008). Positively selected sites of scorpion depressant toxins: possible roles in toxin functional divergence. Toxicon 51, 555-562. doi: 10.1016/j.toxicon.2007.11.010

Toju, H., Abe, H., Ueno, S., Miyazawa, Y., Taniguchi, F., Sota, T., et al. (2011). Climatic gradients of arms race coevolution. Am. Nat. 177, 562-573.doi: 10.1086/659624

van der Meijden, A., Coelho, P., and Rasko, M. (2015). Variability in venom volume, flow rate and duration in defensive stings of five scorpion species. Toxicon 100, 60-66. doi: 10.1016/j.toxicon.2015.04.011

van der Meijden, A., Coelho, P. L., Sousa, P., and Herrel, A. (2013). Choose your weapon: defensive behavior is associated with morphology and performance in scorpions. PLoS ONE 8:e78955. doi: 10.1371/journal.pone.007 8955

van der Meijden, A., Herrel, A., and Summers, A. (2010). Comparison of chela size and pincer force in scorpions; getting a first grip. J. Zool. 280, 319-325. doi: 10.1111/j.1469-7998.2009.00628.x

van der Meijden, A., and Kleinteich, T. (2017). A biomechanical view on stinger diversity in scorpions. J. Anat. 230, 497-509. doi: 10.1111/joa.12582

van der Meijden, A., Koch, B., Van der Valk, T., Vargas-Muñoz, L. J., and Estrada-Gómez, S. (2017). Target-specificity in scorpions; comparing lethality of scorpion venoms across arthropods and vertebrates. Toxins 9:312. doi: $10.3390 /$ toxins 9100312
Villar-Briones, A., and Aird, S. (2018). Organic and peptidyl constituents of snake venoms: the picture is vastly more complex than we imagined. Toxins 10:392. doi: 10.3390/toxins10100392

Warburg, M. (1998). Qualitative and quantitative analysis of intra-and interspecific behavioural patterns among scorpions. J. Ethol. 16, 115-121. doi: 10.1007/BF02769290

Weinberger, H., Moran, Y., Gordon, D., Turkov, M., Kahn, R., and Gurevitz, M. (2009). Positions under positive selection-key for selectivity and potency of scorpion $\alpha$-toxins. Mol. Biol. Evol. 27, 1025-1034. doi: 10.1093/molbev/msp310

Wigger, E., Kuhn-Nentwig, L., and Nentwig, W. (2002). The venom optimisation hypothesis: a spider injects large venom quantities only into difficult prey types. Toxicon 40, 749-752. doi: 10.1016/S0041-0101(01)00277-X

Wullschleger, B., and Nentwig, W. (2002). Influence of venom availability on a spider's prey-choice behaviour. Funct. Ecol. 16, 802-807. doi: 10.1046/j.1365-2435.2002.00686.x

Yahel-Niv, A., and Zlotkin, E. (1979). Comparative studies on venom obtained from individual scorpions by natural stings. Toxicon 17, 435-446. doi: 10.1016/0041-0101(79)90277-0

Young, B. A., Lee, C. E., and Daley, K. M. (2002). Do snakes meter venom? Bioscience 52, 1121-1126. doi: 10.1641/0006-3568(2002)052[1121:DSMV]2.0. $\mathrm{CO} ; 2$

Conflict of Interest Statement: The authors declare that the research was conducted in the absence of any commercial or financial relationships that could be construed as a potential conflict of interest.

Copyright (C) 2019 Evans, Northfield, Daly and Wilson. This is an open-access article distributed under the terms of the Creative Commons Attribution License (CC BY). The use, distribution or reproduction in other forums is permitted, provided the original author(s) and the copyright owner(s) are credited and that the original publication in this journal is cited, in accordance with accepted academic practice. No use, distribution or reproduction is permitted which does not comply with these terms. 